\title{
Reciprocal Measures for Arms Stabilization
}

\section{Citation}

Schelling, Thomas C. 2005. Reciprocal measures for arms stabilization. Daedalus 134(4): 101-117.

\section{Published Version}

http://dx.doi.org/10.1162/001152605774431455

\section{Permanent link}

http://nrs.harvard.edu/urn-3:HUL.InstRepos:3425941

\section{Terms of Use}

This article was downloaded from Harvard University's DASH repository, and is made available under the terms and conditions applicable to Other Posted Material, as set forth at http:// nrs.harvard.edu/urn-3:HUL.InstRepos:dash.current.terms-of-use\#LAA

\section{Share Your Story}

The Harvard community has made this article openly available.

Please share how this access benefits you. Submit a story.

\section{Accessibility}




\section{Thomas C. Schelling}

\section{Reciprocal measures for arms stabilization}

\begin{abstract}
There has been a widespread change in the thinking on arms control in the last year or so. Much of it is due to the focus of attention on "measures to safeguard against surprise attack" (to use the official terminology). Although this subject is still listed anachronistically under "disarmament," it is differently oriented. It assumes deterrence as the keystone of our security policy, and tries to improve it. It accepts a retaliatory capability as something to be enhanced, not degraded - something to be made more secure, less accident-prone, less in need of striking quickly to avoid its own destruction, less capable of gaining advantage from a sudden attack of its own. An anomaly of this approach to arms control is that it does not necessarily involve "disarmament" in the literal sense.
\end{abstract}

Thomas C. Schelling, a Fellow of the American Academy since 1967, is Distinguished University Professor at the School of Public Policy at the University of Maryland. At the time of this essay's publication in the Fall 1960 issue of "Dadalus," Schelling was professor of economics and associate of the Center for International Affairs at Harvard University.

(C) 2005 by the American Academy of Arts \& Sciences
Another anomaly, which rather shakes the disarmament tradition, is that weapons may be more stabilizing and less aggressive if they are capable of civilian reprisal rather than of military engagement. A standoff between two retaliatory forces is in some ways equivalent to an exchange of hostages; and "inhumane" weapons, capable of inflicting damage but not able to go after the enemy's strategic forces, acquire virtue because of their clearly deterrent function and the lack of temptation they give either side to strike first.

More important, though, is the fact that schemes to avert surprise attack are manifestly compatible with a national military policy, not a renunciation of it. They emphasize the possibility that one can simultaneously think seriously and sympathetically about our military posture and about collaborating with our enemies to improve it. To propose, as does the notion of "measures to safeguard against surprise attack," that military cooperation with potential enemies may offer opportunities to improve our military posture, opens a new field for imaginative scientific and military thinking, and may eventually enlist the support of the military services themselves. 
Most of this progress is still ahead of us; the revolution in thinking about arms control is barely started. Officially we have taken only the most hesitant steps in defining arms control in a way that does not contradict our national security policies. We still talk officially as though "disarmament" can only save money, without noticing that under the new philosophy it could cost more. We still work officially with an image of disarmament that makes it solely a peacetime (cold-wartime) process of negotiating explicit detailed agreements in a multinational context for the reduction or elimination of weapons, without adequately recognizing that, as in limiting war, limiting the arms race can be a more tacit and less formal process than the "treaty" idea implies. More important, the prevalent image of disarmament is still one that gives the process a uniquely defined end point - the point of no arms at all, or virtually none except in the hands of some international authority or synthetic state that would have the power to police the world against international violence but against nothing else.

The cautious and the skeptical, the pessimists and the realists, have doubts about how rapidly that end point can be approached, whether it will be approached at all, and whether the process once started may not be reversed. But the ultimate goal is rarely challenged except by those who have no interest in arms control. And by far the most frequent argument raised in favor of particular limited measures of arms control, perhaps the most widely persuasive, is that these limited measures are at least "steps toward" the goal of ultimate disarmament. We have not faced up to the implications of the anomaly that "measures to safeguard against surprise attack" are designed to preserve a nuclear striking power, and are not easily construed as just another "step toward" ultimate disarmament. ${ }^{1}$

We still talk about "levels" of armament or disarmament, as though there were only two directions in which to go, up and down, the arms race going in one direction and arms control in the other. We have not yet admitted that, even in the framework of arms control, it could be an open question whether we ought to be negotiating with our enemies for more arms, less arms, different kinds of arms, or arrangements superimposed on existing armaments. We have given little thought even to the weapon system that would be required by that ultimate international authority that might police the world against armed violence, and to whether it, too, would be embarrassed by a "massive retaliation" doctrine that would lack credibility; whether it, too, might be subject to surprise attack; whether it, too, would lack resolution (as some think NATO might lack resolution) to reach an awful collective decision in response to nibbling aggression or bland violation.

The point of this paper is that there is a vast new area to be explored once we break out of the traditional confinement of "disarmament" - the entire area of military collaboration with potential enemies to reduce the likelihood of war or to reduce its scope and violence. It is an area worth exploring because our present military policies and prospects, however we feel about the adequacy of current programs, cannot promise security from a major thermonuclear

1 See T. C. Schelling, "Surprise Attack and Disarmament," in Klaus Knorr, ed., NATO and American Security (Princeton, N.J. : Princeton University Press, 1959), or the shorter version in T. C. Schelling, The Strategy of Conflict (Cambridge, Mass. : Harvard University Press, 1960), chap. 10. 
war; and even modest improvements achieved through cooperation with the Soviets should be welcome.

It is not true that in the modern world a gain for the Russians is necessarily a loss for us, and vice versa. We can both suffer losses, and this fact provides scope for cooperation. We both have - unless the Russians have already determined to launch an attack and are preparing for it - a common interest in reducing the advantage of striking first, simply because that very advantage, even if common to both sides, increases the likelihood of war. If at the expense of some capability for launching surprise attack one can deny that capability to the other, it may be a good bargain. We both have a common interest in avoiding the kind of false alarm, panic, misunderstanding, or loss of control, that may lead to an unpremeditated war, in a situation aggravated by the recognition on both sides that it is better to go first than to go second. We have a common interest in not getting drawn or provoked or panicked into war by the actions of a third party (whether that party intends the result or not). And we may have an interest in saving some money by not doing on both sides the things that, if we both do them, tend to cancel out.

This common interest does not depend on trust and good faith. In fact it seems likely that unless thoroughgoing distrust can be acknowledged on both sides, it may be hard to reach any real understanding on the subject. The intellectual clarity required to recognize the nature of the common interest may be incompatible with the pretense that we trust each other, or that there is any sequence of activities in the short run by which either side could demonstrate its good faith to the other.

Ancient despotisms may have understood better than we do how to tranquil- ize relations between them while hating and distrusting. They exchanged hostages, drank wine from the same glass, met in public to inhibit the massacre of one by the other, and even deliberately exchanged spies to facilitate transmittal of authentic information. And perhaps, having exchanged a son for a daughter in the cold-blooded interest of contract enforcement, they may have reduced tension sufficiently to permit a little affection to grow up in later generations.

$\mathrm{T}_{\mathrm{h}}$ he premise underlying my point of view is that a main determinant of the likelihood of war is the nature of present military technology. We and the Russians are trapped by our military technology. Weapon developments of the last fifteen years, especially of the last seven or eight, have themselves been responsible for the most alarming aspects of the present strategic situation. They have enhanced the advantage, in the event war should come, of being the one to start it. They have inhumanly compressed the time available to make the most terrible decisions. They have almost eliminated any belief that a really big war either could be or should be limited in scope or brought to a close by any process other than the sheer exhaustion of weapons. They have greatly reduced the confidence of either side that it can predict the weapons its enemy has or will have in the future. In these and other ways the evolution of military technology has exacerbated whatever propensities toward war are inherent in the political conflict between us and our enemies. It might be naïve to say that this is an unmixed evil for both us and the Soviets, since it powerfully affects the bilateral contest between us; nevertheless, it is hard to escape the judgment that nature might have been kinder in the way she let our military technology
Reciprocal measures for arms stabilization 
unfold itself over the last decade and a half.

It is interesting - more than that, it is useful - to ask what technological achievements (available both to us and to our enemies) we wish had never occurred, and what technological failures we wish had turned out otherwise. Do we wish the hydrogen bomb had never come along to make intercontinental missiles economical? Do we wish that nuclear-powered aircraft had made airborne alert so cheap that retaliatory aircraft could stay aloft rather than be vulnerable on the ground to a missile attack? Do we hope that no one ever discovers an economical means of nullifying ballistic-missile submarines, so that neither side can hope to preclude retaliation by sudden attack? Do we wish that warning systems were so nearly perfect that "false alarm" were virtually impossible, or so poor that we could never be tempted to rely on them? Do we wish that missiles had never become so accurate that they could be used to destroy an enemy's missiles in an effort to negate an enemy's retaliatory threat? Do we wish that radioactive fallout could not occur, or do we welcome it as a peculiarly retaliatory (and hence deterrent) weapon effect that is of little use in a preemptive attack? Do we wish that secrecy about weapons and weapon production were much more difficult to maintain than it is, or welcome certain kinds of secrecy as a form of mutually appreciated security against surprise attack?

The reason why it is productive to speculate on these questions, rather than merely fanciful, is that arms control can usefully be thought of as a way of changing some of the answers. In addition to what we can do unilaterally to improve our warning, to maintain close control over our forces, to make our forces more secure against attack, to avoid the need for precipitate decisions, and to avoid accidents or the mistaken decisions that they might cause, there may be opportunities to exchange facilities or understandings with our enemies, or to design and deploy our forces differently by agreement with our enemies who do likewise, in a way that enhances those aspects of technology we like and that helps to nullify those that we do not.

If we wish that radar were better and cheaper and less limited by the Earth's curvature, we might make it so by exchanging real estate with the Russians for the construction by each of us of observation posts on each other's soil. If we hope that no one can ever predict with confidence how his own missiles would do, in a surprise attack, against the hardened missile sites of his opponent, we might deny each other the necessary knowledge by banning tests of large weapons in the era in which anyone actually has a missile in a hard underground site that he could use in a weapon-effects test. If instead we wish that each side might preserve the privacy of its railroad lines for mobile missiles, we might jointly eschew certain surveillance techniques; and if we thought that antimissile defenses of missile sites might be more feasible, and retaliatory forces correspondingly less vulnerable, with the further testing of nuclear weapons and their effects, we might look with more favor on continued weapon testing. These considerations are by no means the whole story in arms control, but they do remind us that we and our enemies can both jointly welcome, or jointly deplore, certain technological developments (like the improved accuracy of long-range missiles) and may possibly find ways, jointly, to enhance them or to offset them, 
over and above the things that we can do unilaterally.

T hese examples suggest some of the criteria that can be applied to limited arms-control schemes, and some of the difficulties in implementing them. As to criteria, the first thing to emphasize is that it takes a good deal of strategic analysis to decide whether a particular limitation or augmentation of weapons or facilities is a good one or a bad one. Viewing limited measures on their individual merits, and not as steps in a comprehensive program that can be justified only by a long sequence of steps to follow, one has to ask whether the technological and economic consequences of a particular scheme are or are not conducive to military stability; and the answer is very unlikely to be closely correlated with whether more weapons or fewer weapons are involved, bigger weapons or smaller ones, or even whether notions of "more" and "less," "bigger" and "smaller," can be applied.

Whether we would like to see reconnaissance satellites banned or encouraged may depend, for example, on whether we think they will mainly provide targeting information to the initiator of war or mainly provide warning to a potential defender so that a potential attacker is the more deterred. Whether we like big missiles or not may depend on whether we believe, as so many believed a few years ago, that missiles would be simple and sturdy and hard to destroy in their underground sites or believe as so many fear now that increased accuracies and yields make the present generation of missiles better for a first strike than for a second strike. Whether we wish missile technology to be advanced or retarded may depend on whether or not we believe, as many do, that the next generation of missiles will be easier to protect, easier to hide, or easier to keep moving, and therefore less insecure. Whether one welcomes nuclear-powered ballisticmissile submarines on both sides or deplores them depends on whether they seem to be peculiarly good at surviving and retaliating, and hence "deterrent," or peculiarly good at getting up close for a no-warning strike on an enemy's retaliatory power. And if it were somehow possible to enforce a ban on "dirty" bombs, there would still be a genuine strategic question of whether or not we wish deterrent capabilities to be enhanced by the greater punitive power of dirty bombs, recognizing that comparatively slow-acting fallout may be of much less utility to a potential attacker, whose main interest is to minimize retaliation on himself.

The fact that developments such as
these require strategic analysis before
it can be decided whether they are good
or bad is, aside from being true, discour-
aging. It means that even among the ex-
perts there will be disagreement about
the consequences of any particular pro-
hibition or exchange of military facili-
ties; it may be next to impossible to get
widespread understanding of the rele-
vant arguments, even within govern-
ments. And if fairly detailed analysis is
required, and careful distinctions have
to be made, prohibitions might have
to be specified in equally careful detail
and with equally fine distinctions. This
is certainly an obstacle to negotiation.
Furthermore, any analysis - and any pro-
hibition or agreement or exchange of
facilities that is justified on the basis of
such analysis - is subject to rapid obso-
lescence. The friendly warning satellite
appears, a year later, as a vicious target-
ing aid to the surprise attacker; the net-
work of warning systems originally de-
signed for mutual reassurance proves in


Thomas $C$. Schelling operation to have too high a false-alarm rate; the missile-guidance systems that we deplored because of their extreme accuracy and the advantage they would give the attacker may prove, after we outlaw them, to have been the main hope for mobile missile systems desired for their invulnerability and hence for their stability. By the time we reach agreement on precisely what to allow in our satellites, where to place our radar, or what missiles to ban, new evidence or new analysis comes along to suggest that the justification of the particular scheme we are about to subscribe to is all wrong.

Finally, by the time we look at individual schemes in sufficient detail to judge whether their strategic implications are "good" for both us and our enemies, we may have narrowed them down to the point where they are intolerably biased. It is probably a mathematically sound principle that the more measures we put in a package, the more their bilateral biases will cancel out, and hence the greater will be the joint gain relative to the competitive advantage. This may mean that once a potential arms-control system is dissected into sufficiently small pieces to apply the right kind of analysis, we shall have more individual bargaining counters too small and too biased for the negotiating process.

The recent negotiations on weapon
tests may prove to be typical. First, there
has been almost no public discussion of
whether the further testing of weapons
and weapon effects would really be con-
ducive to the development of greater bi-
lateral military stability or instability
over the coming years. ${ }^{2}$ Even if the pub-
2 That is, whether further testing would main-
ly facilitate the development of more secure re-
taliatory weapon systems with better commu-
nication and control, less subject to accident
and false alarm, or instead would mainly en-

lic could be got interested in this crucial question, it would be unlikely to have the information it would need to judge the answer. (There has been a good deal of public discussion of the merits and possible demerits of preventing the further spread of nuclear weapons to small countries, but remarkably little discussion of just how a test ban would obstruct the spread.) Second, while it may seem a mischievous stroke of fortune that somebody discovered, between the two conferences, facts or ideas that made the policing of a test ban appear more difficult than it had appeared the year before, this may be exactly what we have to expect in every case. If today we had "completely solved" the new technical problems introduced by the "decoupling" technique, we should still have to be prepared for somebody's discovering next year a new possibility that had been overlooked, one that contemporary detection technology could not yet cope with.

The test-ban discussions also illustrate that, when an issue has been narrowed down, the bias in the advantages may seem to outweigh the joint advantages. There is more controversy, and understandably so, over whether a prohibition on small-weapon tests is in the American interest, than on whether a prohibition covering the whole spectrum is.

But of all the characteristics of the present test-ban negotiations, the most

hance the potency of weapons for preemptive attack and aggravate the urge, when in doubt, to strike quickly and without restraint. The answer is by no means obvious for the period immediately ahead. It should be noted that tests involve not only new-weapon performance but weapon effects on previously untested targets, and the latter may be especially relevant to such things as anti-ICBM defense, civil defense, and the vulnerability of fixed or mobile weapons, warning systems, and communication and control systems. 
significant may be that we have had a moratorium for some time without a formal agreement. (We do not, of course, have rights of inspection; so we cannot be sure that the moratorium has been kept; but it likely has been, except possibly for the most easily disguised tests.) And this moratorium resulted from no detailed negotiations, no careful specifications, and no written documents to be initialed and ratified. I do not think this result can be wholly explained by the pressure of public opinion. Part of the motivation must be that, whatever one side is sacrificing in improved technology, the other side is also foregoing tests, and each would probably resume them if the other did. Thus the main sanction of an arms-control agreement - the expectation that each will abstain only if the other does - is probably present in this case. It is therefore a genuine instance of "arms control." If it suffers from being tentative, temporary, qualified, and conditional, so might any arms-control agreement, even if duly negotiated and signed; furthermore, who can say yet that the present "agreement," if such we may call it, will not be of some duration?

$\mathrm{H}_{\mathrm{er}}$ clue to a process by which arms control may be reached, and the kinds of arms control that can be reached by that process. Maybe arms control is destined to be something more informal than is suggested by the great diplomatic deployments in Geneva. Maybe limited measures of arms control can be arrived at by quite indirect and incomplete communication; maybe they will take the form of a proposal embodied in unilateral action (or abstention from action), which continues if matched by corresponding action on the other side and only for so long as it is. Maybe instead of arguing about what we should do, we will simply do it and dare the other side to do likewise, or do it and quietly suggest that we would like to keep it up, but only if they find it in their interest to do something comparable.

But if arms control is to be arrived at by a more tacit and informal process, and if we are going to call "arms control" any of the military things that we and the Russians abstain from because of an awareness that as long as each abstains the other probably will too, we should look around and see whether we do not already have a good deal of arms control. If we have, we should look at it closely to see what lessons we can draw.

Offhand, it appears (but a more imaginative examination might prove otherwise) that the tacit understandings we have with the Russians concern what we do with our weapons more than what we possess. ${ }^{3}$ We seem to have some understandings about traffic rules for patrolling bombers; there are apparently certain lines we stay on this side of, lines the Russians presumably can recognize, the crossing of which they can probably monitor to some extent. This is certainly a restraint that we unilaterally observe in the interest of reducing misunderstandings and alarms. As far as I know, the traffic rules are communicated, not explicitly, but simply by behav-

3 A possible exception is civil defense. The extraordinary aversion to civil defense in the U.S. government must be complex in its explanation; but an element is very likely a belief that a genuine civil defense program might open up a new dimension of the arms race, leading either to a "civil-defense race" with the USSR or just to an aggravation of the arms competition. The same may be true in the USSR. An interesting question is how much "clandestine" civil defense the Russians are undertaking, and their reasons for keeping it private. (In pointing this out, the author is not trying to justify the aversion to civil defense.) 
Thomas $C$. Schelling ing in accordance with them (perhaps conspicuously in accordance with them) and possibly by having chosen the dividing lines in such a way that their significance is recognizable. We both abstain from harassing actions on each other's strategic forces; we do not jam each other's military communications, scare each other with fallout from weapons tests, or wage surreptitious peacetime undersea wars of attrition. ${ }^{4}$ We may yet develop tacit understandings about zones and traffic rules for submarines, and may (or may not) develop a tradition for leaving each other's reconnaissance satellites alone. We both very obviously abstain from assassination. The Russians recently "negotiated" (by a process of nudging) a sharper understanding about sharing the Pacific for target practice. It remains to be seen whether the U-2 incident causes certain tacit or latent understandings to come unstuck. 5

In all likelihood we may abstain from the use of nuclear weapons in some limited war, though both sides often seem to denounce officially the notion that a serious limited war should be, or could be, fought without nuclear weapons. Here is an interesting case of an arms limitation that may be tacitly recognized by both sides, and recognized only because each thinks the other may observe

4 Not yet, that is, or not very much. Preserving some of the mutual restraints we now enjoy may be as important an "arms-control" objective as creating more.

5 It seems a correct interpretation that there is still some element of implicit understanding about not transferring nuclear weapons to other countries. Its status is presently a great deal more ambiguous than the author expected a couple of years ago; nevertheless there must be a general awareness on both sides that the restraint of either will be weakened or dissolved by promiscuousness on the other's part. it too, yet one that is not only not formally agreed on but even denounced and denied by both sides. It seems doubtful whether this tacit understanding could be made much stronger by a written document. ${ }^{6}$ A restraint on the use of nuclear weapons may be more persuasive if it seems to rest on the enemy's own self-interest - on his understanding that if he abstains we may too, but only if he does - than if it pretends to rest on the power of a written agreement or on a fiction of "good faith."

I In fact, all of the tacitly agreed limits that do apply, or may apply, in limited war can be construed as a kind of informal arms control tacitly arrived at. My impression is that we and the Russians will go to some length to avoid having American and Russian troops directly engage each other in a limited war, simply because such an engagement might create extremely unstable expectations about whether the war could remain limited. We and the Russians both recognize many legalistic limitations in war, such as the distinction between North Koreans and Chinese, between volunteers and regulars, between the provision of materials to an ally and the provision of manpower, between doing an ally's reconnaissance for him and doing his bombing, perhaps even the distinction between local airfields that are fair game because they are on the ground within a disputed country and the decks of carriers offshore that might for some reason be construed as "sanctuary."

6 It could be made much stronger by various unilateral actions. One would be to increase our capability to get along without nuclears in limited war. Another would be to add symbolic support to the understanding; the test-ban negotiations - especially if a formal agreement is reached-almost certainly do this, whether they are intended to or not. 
Most of these limits are arbitrary, conventional, and casuistic - purely matters of tradition and precedent. For that reason they are uncertain and insecure; nobody is even nominally committed to honor them. But they demonstrate that it is possible for potential enemies to arrive tacitly, or by indirect communication, at a meeting of minds about some rules, and about how to interpret intentions through the way one operates and deploys his resources. Most important, the limits that can be observed in limited war are a powerful demonstration that sheer self-interest - the recognition of a need to collaborate with an enemy in wartime, to reach understandings that transcend the formalities of explicit communication; the recognition of a mutual interest in avoiding accidents, incidents, misunderstandings and unnecessary alarms, and in holding to any constraints that can be found - can provide potent sanctions that need not rest on explicit negotiation and formal agreements.

We may, then, increase our understanding of the nature of arms control, what it rests on and how it may come about, by recognizing limited war as a kind of arms control in itself. And perhaps it differs from peacetime (i.e., coldwar) arms control less than we customarily think. Perhaps the psychology and the sanctions and the mode of communication, the kinds of reasoning involved, the lack of formal agreement or even acknowledgment, that typify limited war, represent a more central and typical process of international negotiation than we usually give it credit for.

There is another aspect of limited war that deserves emphasis in this connection. The limits in limited war are arrived at not by verbal bargaining, but by maneuver, by actions, and by statements and declarations that are not direct com- munication to the enemy. Each side tends to act in some kind of recognizable pattern, so that any limits that it is actually observing can be appreciated by the enemy; and each tries to perceive what restraints the other is observing. For that reason the limits themselves must be clear-cut, must be of an "obvious" character, must be based on qualitative distinctions rather than matters of degree. They must not be too selective, too gerrymandered in discriminating between what is inside and what is outside the limit. They must attach themselves to benchmarks, demarcation lines, and distinctions that come naturally. They must have simplicity. They must take advantage of conventions and traditions and precedents that exist, even if the precedents and traditions are biased between the two sides or a nuisance to both sides. Often they must involve all-or-none distinctions, or across-the-board distinctions like that between land and water, between material and manpower, between two sides of a border, or even some arbitrary but potent and highly suggestive feature like a parallel of latitude. 7

This is certainly true in the case of the use of nuclear weapons in limited war. It is enormously more likely that a limit against any use of nuclear weapons could be recognized, sensed, and adhered to by both sides on condition that each other observe it, than that any particular quantitative limitation, target limitation, fission vs. fusion limitation, or limitation based on who is the "aggressor," could be jointly and tacitly converged on by the participants.

7 For an extensive analysis of tacit bargaining, with special reference to limited war, see chapters 3 and 4 and Appendix A of T. C. Schelling, The Strategy of Conflict (Cambridge, Mass. : Harvard University Press, 1960). 
But the same is certainly true of a test suspension. A tacitly reached moratorium on testing nuclear weapons - mutual and reciprocal but essentially unilateral on both sides - is much more likely to be stable and durable, much less likely to be eroded by ambiguous behavior, than a selective moratorium. If we and the Russians are very selective in our unilateral restraints, each choosing the particular yields, altitudes, fission-fusion combinations, and localities for tests, it seems unlikely either that both sides will hit on the same limitations and maintain them with confidence, or that both will hit on "equivalent" though different restraints.

To some extent, then, the gains and losses of a particular agreement, i.e., the way any particular understanding that is reached may discriminate between the two parties (or among more than two parties), are likely to be dictated somewhat by the elements of the problem, and not altogether by the detailed preferences of the parties to the understanding or their bargaining skill. An absolute ban on weapon tests, for example, or any other across-the-board prohibition, is somewhat arbitrary in the way it distributes the advantages; but perhaps some of its appeal is precisely in the fact that it is somewhat arbitrary, somewhat determined by chance or by the very structure of the problem, dictated by circumstances rather than by either side to the other.

$\mathrm{I}_{\mathrm{f}}$ trol - or let us call it "mutual arms accommodation" - with our enemies is going to be tacit and informal, a matter of reciprocated unilateral actions and abstentions, we need to take seriously the problem of communicating with our enemies about what we are doing, and of reaching understandings with them. In some respects informal communication is easier, in some ways harder; the process is different from that of formal, explicit, detailed negotiation, and imposes different requirements. Informal communication is usually ambiguous; a government speaks by hint as well as by overt statement and proposal, it speaks indirectly through the medium of press conferences, leaks of information, and remarks to third parties. It speaks with many voices, in the executive branch, in the congress, and even in private articles and news stories that are "inspired" or are inferred to be so. And it speaks through the actions it takes. ${ }^{8}$

The differences should not be exaggerated; even when large teams of professional diplomats and technical experts are assembled in Geneva, much of the communication takes these other forms. Nevertheless, the strategy of communication is different, particularly because of the greater need in informal negotiations to reach a real understanding. In formal and explicit negotiation, what eventually matters is to a large extent what gets written down and agreed to; even if there was not a meeting of minds, there may have been a meeting of words that provides a record of the expectations of both sides and the obligations perceived. In informal negotiation the ultimate sanction depends less on a piece of paper than on the clarity of the understanding reached. If one behaves in a particular way, in anticipation of the other's reciprocation, there is a need to make clear precisely how one is behaving, with what mutual purpose in mind, so that the other can read the proposal in it, infer what would constitute reciprocation, and design its own behavior accordingly.

8 In a sense, the abortive summit conference of May 1960 did not involve less "negotiation" just because the meeting never took place. 
There is furthermore a greater need to be persuasive. In explicit negotiation, it may be possible to reach an agreement whose terms are reasonably well understood without agreement on principles or any reciprocal understanding of each other's motives. If the letter of the agreement is clear, the spirit can remain somewhat in doubt. In informal negotiation, the spirit bears most of the burden; and if the idea behind what we think we are doing is not perceived by our partner (enemy), what we expect of him - or what we may reasonably be expected to expect of him - may be too dimly perceived to be the basis for genuine reciprocation.

Suppose we decide to put more emphasis on ballistic-missile submarines, for example, in the belief that they are peculiarly "stable" weapons because of their lesser susceptibility to destruction in case of a surprise attack and because they are not so much under obligation to strike quickly in the event of an ambiguous warning (or war itself), or else because their smaller warheads, with possibly a lesser degree of accuracy as compared with ground-based missiles, makes them less of a threat to the enemy's retaliatory forces and more of a genuine deterrent. Suppose we decide that we could afford to do this only if the enemy himself oriented his own strategic program toward similarly "stable" weapon systems. It might not be at all clear to the Russians what our motives are, or what the conditions were for our going through with the program. Or suppose we have a crash program for the development of a more secure groundbased missile force, this program to be financed by a sharp increase in the defense budget, with a good deal of expenditure on command, control, and communication arrangements so as to reduce both the vulnerability of our weap- ons and their sensitivity to accident or false alarm. In particular, suppose that our budget rises because of increased outlays associated with our desire for a slow reacting force, rather than one that must react rapidly. In such circumstances, our actions may be stabilizing or destabilizing, depending on whether the enemy can perceive that we are making the world safer for him rather than increasing his need (and ours) to jump the gun in a crisis. If we institute an airborne alert, it may be important to do so in a way that enhances the apparent as well as the real security and stability of our retaliatory weapon systems. This might mean that we would have to choose deliberately, say, flight patterns that manifestly enhance the security of our forces rather than the speed with which they could initiate a surprise attack of their own.

By far the most important prerequisite is that we understand our own motives well enough to take actions that are consistent with a deterrent philosophy, and well enough so that we can articulate it to ourselves. If we have such a philosophy, and if our actions are consistent with it, and if for our own purposes we articulate that philosophy in explaining our budget decisions here at home, we are probably well on the way to conveying that philosophy persuasively to our enemy, if he is at all receptive. A special problem here is that our overt position on disarmament must not be too inconsistent with the philosophy that we are trying to display and get across to our enemy. If, for example, we really believed in a policy of collaborating with the Russians to develop a stable situation of mutual deterrence, and if we determined to make important changes, to this end, in the configuration of our weapons but these changes were not in the direction of general disarmament, 
we would put a double burden on our communication if the front we presented on arms-control questions bore no relation to that philosophy. This does not necessarily mean that we have to speak in our formal disarmament diplomacy in a manner that is sincere and consistent with what we are fundamentally trying to get across to the Russians. It may just mean that our insincerity should be as manifest as the inconsistency, so that when we do contradict ourselves the Russians know that this is for show and that they should look for the real message elsewhere. Still, it would help if we could find the diplomatic courage to shift even the formal discussions of arms control more into accord with our basic military policy, at the same time as we try to adapt that military policy in directions that the Russians can appreciate and reciprocate, so that disarmament negotiations can help a little, or at least hinder as little as possible, the development of a genuine understanding.

Even so, it is still an unanswered question whether the Russians are at all disposed to participate in any "mutual arms accommodation" with us, beyond what we already do in a tacit way. And it is a difficult technical question whether, even if they are disposed to cooperate with us and appreciate the principle of stable retaliatory systems with minimum proclivity toward false alarm and minimum temptation toward surprise attack, there are any promising actions to be undertaken. Weapon systems can rarely be classified indisputably as firststrike or second-strike weapons, as "accident-prone" or "accident-proof"; a good deal of technical analysis has to lie behind a judgment, many of the technical judgments may not be made equally by us and our enemies, the judgment has to be made in the context of an evolving weapon system for which facts are really only forecasts, and what is known today may no longer be true tomorrow. It is, furthermore, too much to expect the massive bureaucracy of our defense establishment and our foreign service, and the partisan conflicts in Congress, to produce and maintain a coherent philosophy and transmit it with high fidelity to a suspicious enemy whose receptivity and reasoning processes we can only poorly evaluate. But it is worth trying.

$\mathrm{O}$ ne possibility, already adverted to, is to design our military forces conspicuously and deliberately in the direction of deterrence, stability, and slow reaction. That is, to articulate as a policy the design of a strategic force that is peculiarly good at waiting out crises, at surviving a surprise attack, and at punishing an attacker ex post facto, and not particularly good at initiating a preventive attack, not in need of responding rapidly to warning.

This may not be a bad policy to follow unilaterally; but the advantage of pursuing it is greater if the enemy pursues it too. The more each side perceives the other as designing his force for a sudden preemptive attack in a crisis, or for a premeditated surprise attack, the more one is tempted himself to develop a quickreacting system, one that is peculiarly suited to catching the enemy's military forces before they have left the ground. Thus to some extent such a policy is a conditional policy; the motive is greater if the principle is reciprocated by the enemy.

It would be extraordinarily difficult, perhaps impossible, to negotiate a detailed understanding of precisely what kinds of weapons in what configurations, and how deployed, would meet the "stability" criterion. For that reason the idea may not be one that lends 
itself to explicit detailed negotiated agreements. But that does not rule out the possibility that both sides may perceive value in pursuing such policies in a general way, and may recognize that their own behavior not only helps the other side pursue a similar policy but helps to induce it by the tacit promise of reciprocation. As mentioned above, we already do this in such matters as the traffic rules we both unilaterally observe and reciprocate; there may be a good deal of room for gradually extending this kind of reciprocal unilateral action, even though the subject may never appear on the agenda of a diplomatic negotiation.

Compared with a peaceful world disarmed, schemes to stabilize mutual deterrence are a poor second best; judged against the prospect of war, measures to make it less likely may be attractive. This point of view will not appeal to any who believe that war results from the sheer existence of arms and the temptation to use them, or from the influence of militarists in modern society whose prestige increases in proportion to the arms budget, and who believe that distrust is only aggravated by people's acting as though distrust exists. History shows, it is said, that man cannot live in a world with arms without using them. History rarely shows anything quite that universal; but even granting it, the question is not whether it is asking much of man to learn to live in a world with arms and not to use them excessively. The question is whether it takes more skill and wisdom for man to learn to live in a world with arms and not to use them than it does for man to disarm himself so totally that he can't have war even if he wants it (or can't want it any longer). If modern social institutions are capable of achieving disarmament in the first place, and of avoiding arms races in per- petuity thereafter, perhaps they are capable of supporting a world with arms without war. Those who argue that peace with arms is impossible but act as though peace and disarmament are not, may be using a double standard.

And it must be remembered that total disarmament, even if achieved, does not by itself preclude subsequent arms races; nor does a good start toward total disarmament preclude a violent reversal. To the extent that an arms advantage is more easily obtained when the level of armaments on both sides is low - to the extent that the consequences of cheating are greater in a world with few arms arms races might become more violent, the lower the level of armament from which they start. Particularly in a world in which the pace of scientific progress is rapid but jerky, uneven as between countries, and full of opportunities and uncertainties for weapons development, it is not at all clear that the world would be less uneasy about arms advantages if each side continually thought of itself as nearly naked. What can explain the complacency of the American response to the first Soviet sputnik except a feeling (superbly rationalized) that the existing level of arms provided so much security that no single new achievement, or even a revision of the comparative time schedules by a year or two, could quite upset the balance.
$\mathrm{A}_{\text {nother area of possible cooperation }}$ is in damping the arms race through the exchange of information. I am not much impressed with the budgetary fury of our participation in the arms race, but it is not hard to imagine that the budget- ary arms race might get into much high- er gear. If it does, part of the motivation (at least in this country) may be due to uncertainty about the level of armament on the other side. The "missile gap" that 
one estimates, or feels obliged to assume to exist in the absence of information, may exceed the actual missile gap, causing a more frantic increase in armaments than would be undertaken with better information. And it may induce reciprocal action on the other side, which also wishes to avoid an intolerably unfavorable imbalance.

To illustrate: suppose that either side felt reasonably secure against sudden attack as long as its enemy's numerical superiority in missiles never reached, say, 2 to 1 . In this case, just knowing what each other possesses and is producing could make possible a stable equilibrium at a modest level of strategic armaments, while ignorance of the enemy's strength might seem to require an unlimited effort to avoid falling too far behind. With actual weapons such simple calculations are of course impossible; but the principle is valid.

An important difficulty of applying it, though, is that the ways by which one can get authentic information about the other's present and projected strength may provide more strategic information than the other side can tolerate. ${ }^{9}$ A special difficulty is that the Soviets may already know most of what they need to know for this purpose; it is mainly we who do not.

But it is interesting that they might possibly prefer that we know the truth. If in fact we are on the verge of a crash program based on an exaggerated estimate of what they have already done, it could cost them money (and perhaps an increase in the risk of war) to keep

9 Also, one side yields a bluffing or bargaining advantage if it reveals that its weaponry is less impressive than may have been thought. It loses, too, the possibility of surreptitiously achieving a dominant superiority. But losses of this kind are the price of arms control in the first place. up with us. It is also interesting that the truth is probably not something that they could readily reveal on their own. They have to find some way of giving us evidence for believing the truth (or a less exaggerated estimate of the truth) and give it in a way that does not yield targeting and other information that they would find intolerable. The fact that this intelligence gap is mainly on our side does not preclude Soviet interest in some means of conveying the information to us, and it does not obviate the need for cooperative techniques for receiving it.

$\mathrm{M}$ easures to prevent "accidental war," war by misunderstanding, war by false alarm, are another possibility. One aspect of this has been mentioned: the reciprocal development of the kinds of forces and modes of behavior that minimize accidents or their consequences, minimize alarms and misunderstandings, minimize the need to react quickly in the face of ambiguous evidence. But there is another type of joint or reciprocal activity that could help. It would be to arrange in advance, even if crudely and informally, communication procedures, exchange of information, and inspection facilities, for use in the event of an accident, alarm, or misunderstanding that created a crisis. Part of this is just procedural - making sure that we and the Russians have the same idea about who gets in touch with whom when communication or bargaining is suddenly required. Part of it is intellectual - thinking ahead of time about how one would go about reassuring the Russians in the event they had a false alarm, and what we could demand of them for our own reassurance if we ever got ambiguous evidence. Part of it is physical making sure that, if we should need inspectors on a particular scene within a 
few hours to verify that something was an accident, or to verify that the Russians were calm, or to verify that the Russians were not taking actions we thought they were taking, the necessary inspectors and equipment would be available within a few hours' travel time from where we would need them. Just having some Russians available at strategic points around the United States, able to see things with their own eyes if we suddenly wanted them to and able to report home instantly through authentic channels, might be useful someday. And if we ever want them, we may want them in a hurry; there may not be time to identify them, brief them, ship them over here, and train them for their job, once the accident occurs or the crisis is on or the misinformation filters through the Russian warning system. ${ }^{10}$

T here is a more ambitious possibility. Neither we nor the Russians at the present time take arms control terribly seriously; we do not view it as an alternative to a war that is imminent. But it is not impossible to imagine crises in which the likelihood of immediate war would become a grave preoccupation. Once the threat of imminent war rises above some threshold, the mere consciousness that each side is preoccupied with it - and with the importance of being the one to start it, if it should come - will aggravate the propensities that already exist. It is perfectly conceivable that in a real crisis there would be a sudden and drastic change in the attitudes of both sides toward arms control. "Preventive arms control" might begin to look like a risky but attractive alternative to a possibly

10 A more extensive discussion of this point will appear in T. C. Schelling, "Arms Control: Proposal for a Special Surveillance Force,” World Politics (October 1960). inevitable preemptive war. Sudden and drastic "measures to safeguard against surprise attack" might have to be negotiated on an acutely demanding time schedule.

If so, success may depend on whether one or both sides is intellectually prepared for the contingency, whether some understandings have been reached in advance, and whether certain facilities can be improvised to monitor whatever arrangements might be forthcoming. One of the important "limited" armscontrol measures that we might take in advance of such a crisis, either by ourselves or with our enemies, either informally or explicitly, is a development of understandings, procedures, personnel, and equipment, of an imaginative and adaptable sort, capable of going into action at such time as we and the Russians both decide that now is the time for arms control and we can't wait.

A final possibility, a pessimistic but
a serious one and one suggested by the
analogy between arms control and limit-
ed war, is the role of arms control in gen-
eral war if general war occurs. We usual-
ly think of arms control or deterrence
as having failed if war breaks out; and
so it has, but it can fail worse if we give
up at that point. It is not entirely clear
that a general war - a war between the
UsA and the UssR, involving their stra-
tegic forces on a large scale - would nec-
essarily be unlimited either in the way it
would be fought or in the way it would
be concluded. Particularly as we come
to think about an inadvertent war - one
that results by some kind of accident or
misunderstanding, or one that is reluc-
tantly initiated by the Russians or by us
in the belief that it is urgent to preempt
at once - it is worthwhile to consider
whether fury is the only guide we need
in conducting the war, and whether the

A a serious one and one suggested by the analogy between arms control and limited war, is the role of arms control in gen eral war if general war occurs. We usually think of arms control or deterrence as having failed if war breaks out; and so it has, but it can fail worse if we give up at that point. It is not entirely clear that a general war - a war between the USA and the USSR, involving their strategic forces on a large scale - would necessarily be unlimited either in the way it would be fought or in the way it would be concluded. Particularly as we come to think about an inadvertent war - one that results by some kind of accident or misunderstanding, or one that is reluctantly initiated by the Russians or by us in the belief that it is urgent to preemp at once - it is worthwhile to consider in conducting the war, and whether the 
exhaustion of weapons on both sides is the only condition for terminating it.

It is commonly taken for granted that if the Russians initiate a general war it would be in a vicious effort to exterminate us both as a nation and as a people, and that they would be so impatient to do this as to spend valuable weapons to create civil damage at the outset. But it is not obvious that a coldly calculating enemy would afford himself the luxury of going after cities and people when there are more urgent targets that he has to destroy in order to reduce the scale of our retaliation. Nor is it obvious that an impetuous attacker, one whose motivation is partly the fear that if he does not strike first he will be second, would be immune to the thought that he might want to surrender if the thing went badly, to accept our surrender if it went well, or to negotiate a truce between those extremes. If there is no immediate strategic need to kill our people, it may occur to him that they are worth more alive than dead; the threat of killing them gives him something to bargain with in the course of the war or at its termination. Similarly for us: if the war was a mistake we might be more interested in minimizing the consequences of the error, whosever error it was, and in maintaining the possibility of a negotiated outcome that limited damage on both sides. For this bargaining purpose, live Russians and our unspent weapons are assets, and about the only ones we'd have.

The subject is a complicated one and cannot be decided here. It has to be acknowledged that there are dangers in suggesting to the Russians that we are even aware of the possibility that an attack on us might not be cataclysmic for us both. But the possibility is so universally unmentioned and so terribly important that it deserves to be brought into the open for study. Its relation to arms control is that the mere possibility of limiting a general war between us and our principal enemy may depend on some understanding, tacit and informal as it may be, that we share ahead of time. There may be little national advantage in abstaining from certain targets in the event of war, or in attempting to communicate, unless the enemy can be alert to what is going on.

Te erminating a war through anything other than the sheer exhaustion of weapons on both sides would require some form of arms control. It is a noteworthy characteristic of a possible World War III that even unconditional surrender may be physically impossible. How do the Russians persuade us that they have destroyed (or are prepared to destroy or deliver us) some or all of their significant weapons and are prepared to submit to our political demands? We cannot even trust them not to test weapons under a test-suspension agreement; in circumstances infinitely more desperate, when a one-hour pause in the war may be of strategic benefit to somebody, if they send us an urgent message acknowledging their guilt in the war and proposing that we preserve our world by letting them surrender to us, are we likely to be able to do anything? If they are fooling, and if we are fooled, the cost will be tremendous; if they are not fooling and we choose to ignore them, the cost will be tremendous. Can we think of what they might do to prove that they mean it? Have we got the facilities to monitor them and to police them? Have we incorporated in our strategic forces, and in the operating doctrine of those forces, recognition of their potential role in policing the disarmament by which the war might be brought to a close? 
Actually "surrender" is a poor word here. Anywhere between the two extremes of unconditional surrender by one side or the other, the truce or understanding or scheme for bringing the war to a close might better be described as "disarmament" or "arms control." Historically one might have allowed an enemy, when he "conditionally" surrendered, to keep some purely defensive weapons as a hedge against the victor's violating his promise. This is a kind of asymmetrical disarmament scheme. In the future, at the close of a general war, one might have to allow the conditionally surrendering enemy to retain some retaliatory weapons, these being the only kind that two major powers can use to enforce promises from each other. In effect, "measures to safeguard against surprise attack," possibly onesided, possibly bilateral, and certainly more drastic than any that have yet been considered, might be the minimum requirement of a conditionally surrendering enemy.

Thus anywhere between the two extremes of total surrender, the outcome should be viewed as a disarmament process, with the asymmetry presumably reflecting the degree of victory or defeat. But as remarked above, even the extremes of unconditional surrender require much the same kind of procedure for mutual relaxation, cessation of hostilities, inspection, enforcement, and so forth. Any general war that is terminated by a bilateral understanding, by anything other than the independent exhaustion of weapons on both sides, requires something in the nature of an enormous, complex and dynamic scheme for arms control.

If this possibility is to be left open, we need to anticipate it in the design of our strategic forces and in our plans for their use. It may require special facilities and equipment to bring a war to a close, of a kind not necessarily provided for in a plan that considers only the contingency of an all-out war to the finish. But it also requires some mutual awareness ahead of time, on the part of both our enemy and ourselves, and perhaps some crude and tacit, if not careful and explicit, understanding about the modes and techniques of negotiation in the event of war. 
This article has been cited by:

1. Avinash Dixit. 2006. Thomas Schelling's Contributions to Game Theory. Scandinavian Journal of Economics 108:2, 213-229. [CrossRef] 